\title{
Naive Introspection in the Philosophy of Perception
}

\author{
Maja Spener ${ }^{1}$
}

Accepted: 28 October 2021 / Published online: 22 December 2021

(C) The Author(s) 2021

\begin{abstract}
In this paper I critically examine uses of introspection in present-day philosophy of perception. First, I introduce a distinction between two different meanings of the term 'introspection': introspective access and introspective method. I show that they are both at work in the philosophy of perception but not adequately distinguished. I then lay out some concerns about the use of introspection to collect data about consciousness that were raised in over a hundred years ago, by some early experimentalist psychologists, part of so-called 'Introspectionist Psychology'. As I argue, these concerns apply to current philosophical uses of introspection but they are not acknowledged, much less addressed. I explain this by applying the distinction between introspective access and introspective method. As a result, extant arguments relying on introspection-based phenomenal descriptions are methodologically problematic. These problems do not call into question the use of introspection in theorising altogether. But we need to take more care in how we use it.
\end{abstract}

Introspection is a workhorse in present-day analytic philosophy of perception and it has been for much of the past century. It is the backbone of one of the mainstream philosophical approaches to providing an account of the nature of perception. Behind this is the reasonable demand that a good theory of a given phenomenon should be in some sense recognisably of the phenomenon we start with. An adequate account of perceptual experience, so the thought goes, must do justice to what it is like to undergo a perceptual experience by accommodating its phenomenal character. The approach therefore involves appeal to 'phenomenal adequacy conditions' descriptions of the phenomenal character of experience, or of what experience is like, which are then used to constrain an account of the nature of perceptual experience. Such descriptions are typically held to be sourced in introspection and they are frequently called 'introspective evidence' in relevant philosophical literature (e.g. Crane 2000, 50; Martin 2000, 219).

Maja Spener

m.spener@bham.ac.uk

1 University of Birmingham, Birmingham, England 
In this paper I critically examine such uses of introspection. First, I introduce a general framework for understanding and evaluating uses of introspection in theorising. It draws a sharp distinction between two different meanings of the term 'introspection', both of which I show are at work in the philosophy of perception, but not clearly distinguished. I then use the framework to lay out some basic concerns about the use of introspection to collect data about consciousness that were raised in over a hundred years ago, by early experimentalist psychologists, part of so-called 'Introspectionist Psychology'. As I argue, these concerns apply to current uses of introspection in philosophy of perception but they are not acknowledged, much less addressed. As a result, extant arguments relying on introspection-based phenomenal descriptions are methodologically problematic. The main point of the paper, though, is that these problems do not call into question the use of introspection in theorising altogether. But we need to take more care in how we use it.

\section{Introspective Access and Introspective Method}

The term 'introspection' is used ambiguously in psychology and philosophy. There are two related but distinct notions of introspection in circulation. On the one hand, it is used to talk about a mental capacity we take ourselves to have, comparable to perception or memory. According to this meaning, introspection is a mental process that delivers certain kinds of informational states specifically about our own minds. It generates first-person and private awareness of an individual's own mental states or episodes (of, e.g. experiences, thoughts and emotions). Call this sense of introspection 'introspective access'. On the other hand, the term is used to talk about a type of inquiry, a specific way of deliberately investigating the mind. On this meaning, it is a kind of investigation that involves the employment of subjects' introspective access to their own mental states and episodes. Call this sense of introspection 'introspective method'. 1

\footnotetext{
${ }^{1}$ Introspective access - introspection as mental capacity - is meant to capture a widely recognised aspect of our minds, something that is commonly taken to be part of our mental repertoire. A core assumption I make is that introspective access involves some form of detection or responsiveness to existing mental states. Though not entirely uncontroversial, the assumption offers significant theoretical leeway because detection or responsiveness can be rather loosely understood. It is therefore compatible with a great variety of accounts of introspection. Importantly, it does not presuppose a perceptual or quasi-perceptual account of introspection (e.g. Armstrong 1981, Lycan 2003, Morales Forthcoming) but it is consistent with many other accounts, such as constitutive views (e.g. Shoemaker 1994, Gertler 2001), and even pluralist views (e.g. Prinz 2004, Hill 2009). Discussions of introspection often overlap with discussions of certain kinds of self-knowledge but the relationship is complicated (for an excellent overview of this issue see (Schwitzgebel 2019)). Self-knowledge is not always considered to be introspective knowledge, at least not in terms of the core assumption above. For example, central cases of self-knowledge are sometimes taken to involve a creative or self-fulfilling process, where the act of self-attribution alone brings the attributed state into existence (e.g. Moran 2001). Another cluster of views holds that self-knowledge of one's mental states, or at least of certain classes of mental states, is primarily derived from available evidence about the external world (e.g. Dretske 1999; 2003, Tye 2000, Byrne 2018). The latter approach is often motivated by the so-called 'transparency thesis'. See footnote 1 for further comment on how this bears on the focus of the current paper, where the transparency thesis plays an important role.
} 
A good way to capture the importance of this distinction is when considering the frequently asked question about whether introspection is reliable. We may ask about reliability in relation to introspective access or to an introspective method. They are very different questions to ask in each case.

Suppose we ask whether introspective access is reliable. What we want to know is whether introspective access tends to produce accurate states of awareness of our own mind (yielding or providing the basis for true beliefs about or knowledge of our mental states and episodes). We are also interested in the range of its reliability, under which types of circumstances and concerning which types of content deployment of introspective access tends to produce accurate states awareness (Goldman 2004). When asking analogous questions about, e.g. perceptual access we recognise that there are in-built limitations because not everything in the world is perceptually discriminable. Similarly, assuming that introspective access has at least some epistemic value, we can ask which aspects of our mental lives can be reliably introspectively accessed.

On the face of it, introspective access comes in a variety of flavours. Three modes of introspective access are overall recognised regularly in philosophy and psychology (e.g. Brentano 1874, James 1890/1981, Armstrong 1981, Kriegel 2015): we seem to be able to gain first-personal and private awareness of some of our own thoughts and experiences by deliberately focussing on them, by remembering having them, and by peripherally apprehending them as we go about attending to other things. All three modes are pre-theoretically recognised mental phenomena, starting points for theorising. In listing them here, no specific account is assumed. Adequate accounts of them may lead to revision of how many there are at bottom, and to a better understanding of the underlying form of cognitive engagement involved.

Thus, there is an attentional mode of introspective access in that we can deliberately reflect and focus on our ongoing conscious thinking and experiencing. For example, I might focus on how bad my headache is or on the sluggishness of my thinking, or on the size of my visual field as I am looking across the room. Call this mode of introspective access 'inner attention'. ${ }^{2}$ Secondly, there is a memory mode: we can recall having had various kinds of mental states and episodes just earlier. For example, I might remember how two different auditory experiences seemed to compete for dominance a moment ago, or feeling a surge of elation. Call this mode of introspective access 'retrospection'. Thirdly, there is a passive-peripheral mode of introspective access, a way of being non-focally aware of aspects of one's experiences as one is having them. For example, I might be aware of experiencing

\footnotetext{
${ }^{2}$ I want to emphasise that the label 'inner attention' does not imply a perceptual model of introspection or any other model of introspective attention.
} 
visually and auditorily as I am attending to a chirping bird perched on a branch. Call this mode of introspective access 'inner apprehension'. These modes of introspective access are significantly different from each other it seems, involving attentional, memory and peripheral processes respectively. (Though some of them might turn out to be rather similar to non-introspective mental capacities.) As a result, the reliability question about introspective access is likely to have rather different answers in each case.

Suppose that we ask whether an introspective method is reliable. This is a question about introspection as inquiry. What we want to know here is whether a specific method of investigation employing introspective access tends to produce valid data about the target conscious phenomenon being investigated. There are several factors to be considered when assessing whether an introspective method is methodologically sound. The reliability of an introspective method depends in part on the reliability of the particular mode of introspective access employed in it. But introspective methods are more than deployment of a mode of introspective access. Rather, they are individuated by the whole observational or experimental context in which the mode of introspective access is embedded, leading to, and including, the data collected. The observational set-up includes, in addition to the specific mode of introspective access to be employed, the choice of stimulus designed to produce the target of investigation, the manner of stimulus presentation, the timing and type of report elicited from the subject, any prior training of the subjects, any instructions given to the subject, as well as any measures aimed at controlling observational process. The reliability of a given introspective method concerns this whole set-up and its relation to the target of investigation, i.e. to the conscious phenomenon that forms the goal of inquiry. A meaningful assessment of reliability treats introspective methods as specific to a context of investigation and as highly complex.

The distinction between introspective access and introspective methods helps to make clear that we cannot equivocate between the psychological or mental upshot of deploying a given mode of introspective access (e.g. a judgement about ongoing experience produced by inner attention) and the output of a given introspective method, i.e. introspective data. The latter is the product of a goal-directed procedure of investigation and the result of a complex set of steps designed to control the conditions in which this data is collected so that it can serve to answer theoretical questions. The former is a mental state or episode resulting from a specific psychological process.

The two notions - introspective access and introspective method - are usually not distinguished very clearly and this has bad consequences for our understanding of both introspection as a mental capacity and introspection as inquiry. As we shall see, the use of introspection one finds in analytic philosophy of perception is no exception to this.

The majority of contemporary philosophers using phenomenal adequacy constraints in their theorising about perception are taking themselves to employ an 
introspective method in some sense. ${ }^{3}$ For instance, Martin $(2000,219)$ sums up the dialectical situation in the debate about the nature of perception in this way:

[W] hat is notable about each of the main traditions [in the philosophy of perception] is not what they seek to defend by reference to introspection, but what they are prepared to reject in the face of introspective support. The sense-datum tradition denies the manifest fact that it seems to us as if we are presented in experience with mind-independent objects and states of affairs in the world around us. The intentional tradition denies the introspective evidence that things apparently sensed must actually be before the mind for one to experience so.

The notion of introspection as inquiry brings with it that of introspection as mental capacity, of course. This is because introspective access to our experiences is presupposed by any introspection-based method, including theorising by appeal to phenomenal adequacy constraints.

It is no exaggeration to say that typically little to no thought goes into selecting the kind of introspective access meant to be at work in deriving the descriptions about the phenomenal character of perceptual experience. Introspection is assumed to be a straightforward psychological capacity that we, as ordinary experiencers and perceivers have and know how to deploy without difficulty. In fact, in many cases the assumption of the appropriate first-person access recedes entirely into the background and philosophers put forward phenomenal appearance claims without ever mentioning how these were acquired. When introspection is specifically introduced in the philosophical debate about perception, the dominant view by far is that it is an attentional phenomenon. Thus, the main mode of introspective access is generally held to be inner attention. Kriegel $(2015,20)$ even calls it 'introspection proper'.

When theorising about perceptual experience, analytic philosophers therefore typically use an introspective method that predominantly employs an attentional mode of introspective access (inner attention). Is this introspective method reliable? As we have discussed, an answer to this question needs to consider not only the reliability of the mode of introspective access employed in it, but also how it is embedded in an overall observational set-up, thus generating the introspective data. To focus our investigation, I first turn to another group of theorists known for using introspective methods: the early experimental psychologists, part of the so-called 'Introspectionist' tradition from the mid-nineteenth to early twentieth century.

\footnotetext{
${ }^{3}$ This is also true of older debates. In discussions of the sense-datum view of perception, for example, Moore $(1903,446)$ speaks of 'refer[ing] to introspection and try[ing] to discover what the sensation of blue is'. It was generally accepted in that debate that the main source of data for philosophers is a kind of inspection or examination from the first-person perspective. Price $(1932,2)$ speaks of 'examin[ing] seeing and touching for ourselves', and of the sensuousness of the experiential given that is 'obvious on inspection', and Firth $(1949,453)$ speaks of 'direct inspection of perceptual consciousness itself'. In addition, many of these early sense-datum theorists insist that the phenomenal claims they are putting forward are based on evidence immediately available to every conscious perceiver and not open to doubt by anyone reflecting on experience (Broad 1923, 236; Lewis 1929, 53; Price 1932, 3). This, too, assumes that the phenomenal datum is robustly available in the context of first-person inquiry.
} 


\section{Old Worries About the use of Introspection}

In this section, I introduce two separate concerns about using introspection in theorising about the mind. They target very different aspects of such use, something we can articulate in terms of the proposed framework based on the distinction between introspective access and introspective method. One concern is about the general observational set-up, the resulting conception of introspective data, and the way it is handled in theorising. The other is about the employment of a specific mode of introspective access in an introspective method. As I will argue in the subsequent section, they apply directly to contemporary philosophical theorising involving introspection.

I set them out by briefly showing that they were recognised and dealt with by central figures in the so-called 'Introspectionist' early period of psychology in the mid-to-late nineteenth and first couple decades of the twentieth century. I focus on three main figures: Wilhelm Wundt, William James, and Georg Elias Müller. ${ }^{4}$ Between them, their views exemplify the advanced state of debate about introspective methods during this period.

The historical route is valuable for several reasons. Contrary to popular misconception, many psychologists in that era had extensive and highly developed views about introspective methods in empirical psychology (for detailed discussion see Spener (Forthcoming)). In the early days of experimental psychology, methodological questions loomed large and were often considered to be of existential importance. Psychologists then were typically well-versed in philosophy, physiology, and psycho-physics, and their methodological discussions centrally engaged with concerns about the role introspection should and could play in psychological and philosophical theorising. Looking at them, we can therefore gain a better understanding of the methodological concerns themselves, but also of possible solutions.

\subsection{The Generalisation Worry}

G. E. Müller devotes a whole section of his comprehensive treatment of introspective methods in research on memory to spell out and roundly reject what he calls 'the method of putative reminiscences' (Müller 1911, 143-7). He notes that this often is the method of choice for certain psychologists and, importantly, for philosophers. The method is rooted in the commonplace tendency to make general psychological claims about ourselves on the basis of having on some past occasion become introspectively

\footnotetext{
${ }^{4}$ Wilhelm Wundt (1832-1920) is fairly well-known in philosophy of mind at least, considered to be the founding father of experimental psychology in Germany. He established the first laboratory dedicated to psychological research at the University of Leipzig in 1879. William James (1842-1910), is, of course, very familiar to English-speaking scholarship in philosophy and psychology. He established the first psychological laboratory in the US at Harvard University in 1874-5. Georg Elias Müller (1850-1934) is less well-known today. His work on memory and attention was highly influential in the development of these fields in empirical psychology. He founded the second psychological laboratory in Göttingen, Germany in 1887.
} 
aware of an instance of such a conscious feature. An example from my own case is that as a bilingual speaker who is completely immersed in their second language, English, it seems to me that I usually still mentally count in my native language, German. I believe this because on several occasions in the past, I have caught myself thinking in German when I am engaged in some counting task.

We regularly make claims about particular conscious episodes on the basis of ordinary introspective judgments made in day-to-day life. All of a sudden something about ongoing experience jumps out or we recall having experienced something in a certain manner. As Müller points out, the data provided by these ordinary introspective judgements about particular experiences are not up to scientific standards. Given their haphazard, uncontrolled collection, they are subject to contamination from a whole range of interference sources, including habit, expectation, confabulation, etc. Still, Müller concedes, they are some sort of 'empirical data which may have a place in the overall consideration' (Müller 1911,144). They can yet contribute in a small way to the body of introspective data that are relevant to theory-construction about a given psychological phenomenon, as long as their evidential limitations are kept in view.

The trouble is that in many cases ordinary introspective judgements of particular conscious episodes are taken by themselves to support generalised claims about experience. In this vein, for example, people claim of themselves that they always learn text by imagining it visually. These general claims, established in the way they are, have no empirical value on Müller's view, since they are not made on the basis of a large enough sample of introspective data about particular experiences that has been collected in a systematic and controlled manner (Müller 1911, 145-7).

Any introspective method producing general claims about experience in this way is therefore scientifically inadequate. For Müller, it is a method only in the extended sense of being some procedure for making claims about conscious experience. ${ }^{5}$

He specifically accuses philosophers of employing introspection in this problematic manner:

[T]he much celebrated introspective method of philosophers was in the end nothing other than the method of putative reminiscences. Sitting at their desk, the philosopher, who typically wants to deal exhaustively with the study of memory over the course of a couple of days or even hours, seeks to determine on the basis of their own recall, how things are with the operations of their memory. The quality of the established results is on a par with that of the method used to establish them (Müller 1911, 147)

\footnotetext{
${ }^{5}$ Examples of such misuse include the practice of sending out questionnaires asking ordinary people to provide such general answers based on their own introspections or asking the subject in question directly for general introspective observations about their experience. Müller $(1911,146)$ mentions e.g. Charcot (1886), lamenting: 'If only we would finally stop the practice of demanding from experimental subjects - indeed, even from younger school children - general information about their psychological behaviour (their conscious learning), and then taking these general claims to be a description of the actual state of affairs! If only we would refrain from sending out questionnaires which demand from their recipients general information about their [conscious] behaviour or methods in this or that respect!'
} 
Müller was an experimental psychologist, of course. Is he right to say that philosophy faces the same methodological strictures driving his generalisation worry? An introspective method gathering data about experience in service of philosophical theorising about mental phenomena like memory and perception is not subject to exactly the same standards as a scientific introspective method in psychology. But it cannot be just any old procedure either. Such an introspective method aims to collect introspective data that is valid for theorising about empirical phenomena: in the case at hand, perceptual experience. That means that the conditions under which the data is collected in a given instance must be conducive to accuracy, ensuring that there is as little interference as possible in the production of it to avoid contamination. Further, the handling of the introspective data must not outrun the information that can plausibly be collected in this manner. Specifically, an application of an introspective method collects data about particular experiences to begin with. If such data is used to make claims about experience in general - especially when the data set is sparse - it should be made explicit how the former can be reasonably taken to support the latter.

\subsection{The Modulation Worry}

William James is often quoted as asserting that scientific psychology requires an introspective method:

Introspective Observation is what we [as psychologists] have to rely on first and foremost and always. The word introspection need hardly be defined - it means, of course, the looking into our own minds and reporting what we there discover. James (1890/1981, 185)

He was also well aware of certain difficulties in employing introspection to this task and spent some time explaining how to work around these. In particular, he acknowledged that there is a long-standing worry about 'the inaccuracy of introspective observation' (187). It was posed forcefully by Comte (1830), who dismissed the prospect of a scientific psychology altogether on the grounds that it would have to use introspection but that such introspection cannot deliver scientifically adequate data (see also Kant 1786, 471).

The starting point is that introspectively reflecting on one's ongoing experiences itself leads to changes in the ongoing conscious situation. Minimally, the mental activity of introspectively reflecting modulates the ongoing flow of experience by contributing to it. But beyond that, it may also change the experiential situation more significantly by not merely adding to, but also altering the ongoing flow. The grounds for this starting assumption range widely, but most commonly they involve a mixture of conceptual and empirical considerations. A common theme is that deliberately attentively reflecting on something is an intention-driven conscious mental activity of some sort. As such, it forms part of the conscious situation when engaged in. What is more, attention is subject to capacity limits, raising the possibility that any attentional activity going on beforehand is diminished once attention to it is engaged. Both of these points imply a change in the conscious situation due to introspective 
reflection. ${ }^{6}$ The worry is then that psychologists cannot exploit introspective reflection on the independently ongoing flow of experience because any introspective data so collected is always confounded by the very activity of introspective reflection itself. This is the modulation worry about introspective methods.

James endorses a solution to the modulation worry proposed by Mill (1907/1865), arguing that while we cannot introspectively attentively reflect on ongoing experience without changing it, we can at least retrospectively access it without changing it. While memory is prone to error and incompleteness in various ways, it does not change what has already come to pass. He says that 'it is only post-mortem that [experiences] become [the psychologist's] prey' (James 1890/1981, 189). The modulation worry can therefore be addressed by selecting a mode of introspective access that is suitable to be employed in an introspective method. According to James (and using the labels introduced earlier), that mode is retrospection and not inner attention.

Wilhelm Wundt also held that introspective methods need to address the modulation worry raised by Comte. For those reasons he too thought that the attentional mode of introspective access cannot serve in a scientifically adequate introspective method (Wundt 1888, 296; 1907, 331; 1908, 164). On Wundt's solution to the modulation worry, the central mode of introspective access suitable for use in an introspective method instead of inner attention is not retrospection but our passive, inner apprehension. Again, the aim is that engagement of introspective access does not change the ongoing flow of experience and on his view our passive, perhaps even automatic, peripheral apprehension of experience as we go along fits this bill. ${ }^{7}$

The modulation worry, while it focusses on a specific mode of introspective access, concerns the employment of it in an introspective method. Thus, James' and Wundt's positive proposals in response to the modulation worry involve not merely selection of different modes of introspective access, but also showing how these can be put to work to generate reliable introspective data in the context of theoretical inquiry. The details of their views - of how retrospection and inner apprehension respectively, are to be employed in an overall introspective method - go beyond the scope of this paper. In each case, however, their goal is to minimise error due to interference from other sources and to maximise the information obtainable in a given situation of introspective engagement. That means, for example, accommodating propensities for various types of memory failures, or managing the fact that passive inner apprehension cannot be engaged in deliberately without turning it into active attentional reflection.

A different kind of solution is proposed by Müller. He distinguishes between what he calls natural conscious episodes and forced conscious episodes (Müller 1911, 73). Forced conscious episodes are experiences that are produced at least partly in response to an intention to attentionally reflect on one's own experiences - they

\footnotetext{
${ }^{6}$ Contemporary versions of it and the connected methodological worry can be found in the science of consciousness under the name of 'observer effect' (e.g. Timmermans and Cleeremans 2015).

${ }^{7}$ Retrospection does play a role in Wundt's introspective methods, but only a secondary, supportive role to the primary role of inner apprehension. See (Spener Forthcoming) for discussion of these different introspective methods.
} 
are the result of having one's flow of experience modulated by such reflection. Natural conscious episodes, by contrast, are experiences that are produced and unfold in absence of intentionally reflecting on one's conscious situation.

Müller, too, accepts that inner attention, actively guided by the intention to reflect on one's own conscious situation, cannot be employed in a method that investigates the flow of natural experience 'as it is' (Müller 1911, 86-7). Any introspective method that tasks the subject to attentively reflect on their ongoing experience is subject to the modulation worry. An investigation of natural experience must therefore employ retrospection instead - here he agrees with James. He points out, however, that inner attention can be employed in an investigation of forced experience. That is, if the explicit target of inquiry - the aspects of our mental situation we want to investigate - includes potential modulation from the introspective activity itself, the effects of attentively reflecting on experience do not present a confound (Müller 1911, 77-8).

But Müller emphasises that in such cases, there are strict limitations on the evidential import of the data collected, otherwise we run into a version of the generalisation worry. We must be careful not to use the results obtained about forced experiences to theorise about experience as such, where this includes natural experience. While such generalisation may be possible, it takes further work - not deliverable by application of the introspective method employing inner attention alone - to establish it.

\section{The Transparency of Experience}

As noted in the beginning of this paper, philosophers of perception are using an introspective method in their theorising about perceptual experience and the mode of introspective access employed in it tends to be inner attention. Primed with the historical discussion in the previous section, we can focus our critical assessment of the reliability of this approach concretely on the two methodological worries about modulation and generalisation. These pose significant problems that are neither acknowledged nor addressed in this area.

Let me show this now in detail by looking at the widespread claim that experience is transparent. Proponents of the transparency claim insist that introspecting the phenomenal character of experience does not lead to awareness of any special experiential objects or properties, distinct from objects and properties normally mentioned in describing the world experienced (e.g. Harman 1990, 39; Dretske 1995, 62; Shoemaker 1996, 100-101). Gow (2016, 724-5), for instance, puts it this way:

According to the transparency claim, when we introspect our perceptual experiences we do not seem to be aware of internal features of our experience. We seem only to be aware of externally located properties.

The transparency claim plays a major role in the debate about the nature of perception. It is considered a centrally important phenomenal description of experience. As Kind $(2010,902)$ notes, 'transparency has often been taken to be a basic datum about our introspective situation' (see also Lycan 1995, 82; Loar 1997, 597; Tye 2000, 51; Gow 2016, 724-5). It serves as introspective evidence in favour of both naive realism and representationalism about perception, and it functions as introspective evidence 
against sense-datum views and qualia views (for an overview see Crane and French 2017).

In our terms, commitment to the transparency claim results from an application of an introspective method to perceptual experience. Furthermore, this introspective method employs the inner attention mode of introspective access. The introspective reflection involved in securing the transparency claim is almost always attentional in character (see e.g. Harman 1990, 39; Martin 1997, 84; Lycan 2003, 21-2; Kind 2010). Standard expressions of it use phrases such as 'turning one's attention inwards', or 'attending to one's experience'. For instance:

Why is it that perceptual experiences are transparent? When you turn your gaze inward and try to focus your attention on intrinsic features of these experiences, why do you always seem to end up attending what the experiences are of? (...) In turning one's mind inward to attend to the experience, one seems to end up scrutinising external features or properties. Tye (1995, 135-6)

The two notions of introspection at work here - introspective access and introspective method - are typically not separated. Introspection is taken to be deliberate inner attention to perceptual experiences in service of philosophical inquiry into the nature of experience: it is held to be the deployment of a mental capacity and then the exploitation of that deployment for theoretical purposes all in one go. The set-up - the observational context in which inner attention is embedded in the theoretical investigation - is hardly commented on, probably because it is extremely compressed and simple.

Insofar as comments are made, though, introspection-based phenomenal descriptions are put forward on the basis of inner attention made in ordinary circumstances with no preparation. For example, Tye $(1992,160)$ samples the relevant introspective data when remembering 'standing on the beach in Santa Barbara a couple of summers ago on a bright sunny day' and looking at the blue ocean. ${ }^{8}$ The literature on perception is filled with examples where the specific phenomenal descriptions are sourced in easy-to-come-by, simple observational set-ups like this ('when I look at the lavender bush/tree/tomato/etc. before me and I turn my attention to my experiences...'). Readers are sometimes invited to pause briefly so that they, too may perform a particular introspective task of their own before continuing.

While there is very little discussion of the choice of this introspective method, the language surrounding it often suggests that it is meant to yield descriptions of phenomenal character from an ordinary perspective, of 'how the subject's situation strikes her when consciously perceiving' (Martin 1997, 84). This introspective method is meant to reveal the phenomenal character of experience pretheoretically apprehended, i.e. not influenced by any philosophical theory or commitment which might lead to distortion of such apprehension. Borrowing from Schwitzgebel (2008) and Phillips (2015, Section 7), let us call this introspective

\footnotetext{
${ }^{8}$ I am ignoring the involvement of memory here, with a considerable gap between the event of recall and the conscious event recalled, making this use of introspection even more problematic.
} 
method 'naive introspection'. The label connotes both the expectation that what is gathered by the procedure is data about experience rather than reflecting theoretical expectation, and also that the manner in which those data are gathered is simple and without any reliance on fancy equipment or laboratories.

In practice, transparency proponents application of the method of naive introspection goes something like this. Step (1) is to get into a situation where they are having a target perceptual experience, perhaps by standing on a beach and looking at the ocean or by going outside and looking at a tree. Step (2) involves attending to the experience they have just induced - in my terminology, this constitutes deployment of a specific mode of introspective access (inner attention in this case). Step (3) is finally to report on what they are aware of upon having attended in this manner: this delivers the introspective data to be used in theorising about experience.

The simplicity of this observational set-up starkly contrasts with some of the careful and highly complex experimental set-ups found in early psychology, especially those of Wundt and Müller. Introspective data was recognised as the output of an overall process in which a given mode of introspective access is embedded in an observational setting in service of pursuing a specific target of inquiry. Analogues of steps (1) and (3) involve detailed, complicated procedures designed to ensure that the deployment of a given mode of introspective access yields information about the target of inquiry that is fit to constrain theorising downstream. In the case of naive introspection as used in the philosophy of perception, almost all the work in procuring the introspective data is done in step (2) by the mere deployment of inner attention towards an experiential situation put in place by step (1), and the move from step (2) to step (3) consists only in articulating the upshot of inner attention. This diminishes the difference between introspective data and the upshot of a mode of introspective access to at best a mere notional one. It is not surprising that the distinction between introspection as mental capacity and as inquiry is not accorded much significance.

The result is, however, that methodological problems such as the modulation worry are obscured. We saw that the modulation worry was taken extremely seriously by early experimental psychologists. James, Wundt and Müller developed their introspective methods in large measure as solutions to that worry - the above mentioned complexity of their methods is a consequence of this. There seems to be no such struggle in contemporary philosophy of perception. And yet, the modulation worry is particularly pressing in relation to the transparency thesis.

The modulation worry, recall is this: inner attention has a potentially distorting influence with respect to gathering introspective data about a given mental phenomenon because reflecting deliberately and attentively on one's own experiences changes the overall ongoing experience by contributing to it or potentially even altering it. Consider, then, the starting point of the modulation worry alongside the transparency thesis:

Modulation Introspectively attending to one's ongoing experience changes the subject's overall experience.

Transparency When introspectively attending to one's ongoing perceptual experience all one is aware of is what experience is as of. 
There is no outright incompatibility between the two claims in terms of competing phenomenal descriptions. ${ }^{9}$ Transparency is a claim about the introspectible phenomenal character of perceptual experience. ${ }^{10}$ But Modulation is not based in an introspectively-sourced phenomenal description. It is not grounded in us becoming aware of modulation effects when introspectively accessing our own experiential situation. There is also no logical or conceptual incompatibility between them.

Still, there is an initial explanatory challenge to accommodate Modulation with Transparency. Modulation says that attentive reflection on the subject's ongoing experiential situation changes it. Transparency says that in introspectively attending to one's perceptual experience all that the subject is attentively aware of are the mind-independent objects and sensible properties presented in experience. But if inner attention changes the ongoing conscious situation by contributing to it, how can it be that in so attending to that conscious situation we 'seem only to be aware of externally located properties' as e.g. Gow in the quote above maintains? Minimally, some work needs to be done in order to explain how the changes in the conscious situation due to the contribution of deliberate attentive reflection on one's experiential situation, go hand in hand with an overall introspection-based awareness of only externally located properties.

This explanatory challenge is manageable in the end, I think, and there is plenty of empirical work on attention that would be relevant (Carrasco et al. 2004, e.g.). While perhaps not without difficulties, Modulation and Transparency can be reconciled from a phenomenological point of view. There are two broad options. One is to say that the changes to the conscious situation brought about by attentive reflection do not affect the introspictable phenomenal character of perceptual experience. The second is to say that these changes do affect phenomenal character and that Transparency is the result of these changes. What is ultimately at stake, however, is how useful Transparency is going to be in the debate about the nature of perceptual experience. For the transparency datum to retain its evidential strength in accounting for the nature of experience, it is important that it represents not merely a partial or significantly incomplete picture of what experience is like. Either of the two options might be held to diminish the force of the introspective datum that all one is aware of are externally located properties because there is reason to think that there are further conscious properties relevant to the experiential situation.

But, in any case, the modulation worry is not about the aptness of phenomenal descriptions, it is about the use of such descriptions in theorising about the mind. Modulation and Transparency are in serious conflict from the point of view of an introspective method designed to deliver empirically valid data fit for theoretical purpose. The main concern raised by the modulation worry is therefore methodological:

\footnotetext{
${ }^{9}$ The transparency thesis has been criticised by appeal to competing introspection-based phenomenal descriptions that indicate awareness of experience itself (e.g. Kind 2003).

${ }^{10}$ Putting it this way skirts over two distinct roles of Transparency in philosophy, namely as a thesis about the phenomenal character of experience and as a thesis about introspecting experience. Here, we are focussed on the first role, but see footnote 11 for its relationship to the second.
} 
given the change in the conscious situation introduced by deliberate attentive reflection on experience, the deliverance of such reflection cannot be taken to be valid empirical data about perceptual experience as such.

It is important to keep in focus that Modulation is not based on any introspective deliverance itself - it is not put forward as a competing introspective datum about what experience is like. The modulation worry it is therefore not grounded in phenomenology. The point, we have seen in the previous section, is this: whatever one is introspectively aware of on the basis of inner attention ought not to be taken to provide accurate information simply of what perceptual experience is like. The flow of experience has been changed by the activity of the deliberate attentive reflection on one's conscious situation. The point holds even if - as fans of Transparency insist introspectively it does seem that all one is aware of is external objects and their sensible properties. The modulation worry does not target the putative transparency datum itself (though it does not endorse it either). It targets the theoretical use of any datum arrived at in this manner. ${ }^{11}$

The critical point needs to be further qualified in light of Müller's helpful distinction between forced and natural conscious episodes (see Section 2.2). Any application of an introspective method using inner attention leads to introspective data about forced experience instead of natural experience. That data (whatever the content) reflects the changed experiential situation of the subject. The transparency thesis is no exception - it is about forced experience in the first instance. The considerations involved in reconciling Modulation with Transparency can be understood in this light, i.e. as ways to understand what the forced nature of such experience might come to. So, properly qualified, the modulation worry does not target the theoretical use of introspective data collected by the method of naive introspection in principle. Rather, it is the use of it to theorise about the natural flow of experience. The transparency datum and any theory built on it, must not automatically be generalised to perceptual experience as such. At this point then, the modulation worry and the generalisation worry intersect.

The problem is that the introspective method of present-day philosophers of perception is meant to deliver introspective data about experience as such. Transparency, for example, captures introspective data that is meant to be used in theorising about

\footnotetext{
${ }^{11}$ There is a cluster of accounts of self-knowledge that are motivated by something like Transparency (though not always restricted to perceptual experience; e.g. Evans 1982, Dretske 1999; 2003, Tye 2000, Carruthers 2011, Byrne 2018). Does the modulation worry undermine the motivation for these transparency accounts of self-knowledge? No. Again, Modulation is not based on a phenomenological datum - it is neutral on what the phenomenal deliverance of introspective reflection is and therefore compatible with Transparency on that score. So if Transparency is indeed an apt description of the relevant conscious situation when introspectively reflecting, then this might plausibly form an adequacy constraint on one's account of self-knowledge. The use of such an introspective datum for this theoretical purpose - to theorise about the nature of first-person-based self-knowledge - is not called into question by Modulation. But in turn, it is unclear how acceptance of a transparency account bears on the issues being discussed in this paper. As mentioned in footnote 1, these views do not accept the responsiveness assumption and it is unclear whether they are in the end accounts of introspection-based self-knowledge. The issue requires further, detailed investigation. But there is no obvious defensive move on behalf of proponents of naive introspection available by appeal to these accounts.
} 
the nature of perceptual experience in full generality. As just argued with the benefit of the historical perspective outlined in Section 2, such use of inner attention to pursue this general aim is wrong-headed. Indeed, the employment of inner attention in combination with the kind of easy-going, ordinary set-up for gathering the introspective data - the overall method of naive introspection exemplified in steps (1) to (3) compounds the problem further. It means that there is not even an attempt to control data collection in ways which render it suitable for use in theorising about experience more generally. Naive introspection therefore does nothing to address any of the standard sources of interference that early psychologists, such as Wundt and Müller, worked so hard to mitigate. As such it can fairly be considered a method of putative reminiscences, with all the concerns raised for it. ${ }^{12}$

Altogether, then, the phenomenology-based arguments in present-day philosophy of perception are not in good shape because the methodology for sourcing the phenomenal descriptions at their heart is unsound. I have not argued that the specific phenomenal descriptions, e.g. those captured by Transparency, are mistaken. They may well be good articulations of how things strike one when one deliberately and attentively reflects on one's experiences. But they cannot carry the theoretical load in the debate about the nature of perceptual experience that they are routinely asked to carry. At least, they cannot do so without further support by addressing the modulation and generalisation worries.

Criticism concerning the use of introspection in theorising about perception is not new (Schwitzgebel 2008, e.g.). If it is made on the basis of an undifferentiated claim that introspection is unreliable, however, the criticism can seem unsurmountable. It can suggest that our choice is either to give up on using introspection in theorising about consciousness and perception or simply to ignore the criticism and continue on regardless. But the discussion in this paper shows that this is not the choice we face in the philosophy of perception (or in other areas where introspection plays a serious theoretical role). Application of the framework for evaluating introspective methods outlined in Section 1 offers a way to make the task tractable. By looking at the history of psychology - especially at the work of certain key figures among the early experimentalists - we can learn that using introspection in theorising is a complex theoretical and practical matter. Their approaches may not be directly applicable to the philosophy of perception, but they provide helpful templates to guide construction of an appropriate introspective method.

Philosophers, along with psychologists, want introspective data about experience that is 'pure', data uncontaminated by other sources and therefore of high theoretical

\footnotetext{
${ }^{12}$ In many respects, naive introspection is most similar to the brand of introspective method characteristic of the so-called 'Würzburg School' in early psychology, among whose members were Oswald Külpe, Karl Marbe, and Narziss Ach. Their work was the focus of much criticism by Wundt and Müller (see especially Wundt 1907, Müller 1911). A key complaint was that the Würzburgers' introspective method employed inner attention without addressing any of the standardly recognised methodological problems associated with it (such as the modulation and the generalisation worries). In the eyes of careful experimentalists like Wundt and Müller, the Würzburgers moreover flouted all sorts of further rules for rigorous data collection and scientific experimentation, so that their experimental results ended up full of confounds and inaccuracies.
} 
value. The history of experimental psychology makes clear that getting introspective methods to deliver such data requires embedding specific modes of introspective access in carefully controlled observational contexts, tailored to the particular experiential targets. This fact has not been sufficiently appreciated in analytic philosophy of perception. Extant uses of introspection in this area - and results derived on their basis - are compromised for this reason. But that does not mean that there is something fundamentally wrong with using introspection to theorise about perceptual experience. We should draw on the early psychologists' work to figure out how to do it better.

Acknowledgments Versions of this paper were presented at the 2020 APA Eastern Division meeting in Philadelphia and at PML5 in St Andrews in August 2019. I thank the audiences at the events for their comments and questions. I am especially grateful to very helpful comments from Gary Hatfield, Peter Pagin, Scott Sturgeon, Henry Taylor, and two anonymous referees for this journal.

Open Access This article is licensed under a Creative Commons Attribution 4.0 International License, which permits use, sharing, adaptation, distribution and reproduction in any medium or format, as long as you give appropriate credit to the original author(s) and the source, provide a link to the Creative Commons licence, and indicate if changes were made. The images or other third party material in this article are included in the article's Creative Commons licence, unless indicated otherwise in a credit line to the material. If material is not included in the article's Creative Commons licence and your intended use is not permitted by statutory regulation or exceeds the permitted use, you will need to obtain permission directly from the copyright holder. To view a copy of this licence, visit http://creativecommons.org/licenses/by/4.0/.

\section{References}

Armstrong, D. 1981. What is consciousness? The Nature of Mind. Heil, J. Cornell: Cornell University Press, 721-728.

Brentano, F. 1874. Psychologie vom empirischen Standpunkt Vol. I. Germany: Duncker \& Humblot.

Broad, C.D. 1923. Scientific Thought. Kegan Paul.

Byrne, A. 2018. Transparency and Self-Knowledge. Oxford: Oxford University Press.

Carrasco, M., S. Ling, and S. Read. 2004. Attention alters appearance. Nature Neuroscience 7: 308-313.

Carruthers, P. 2011. The Opacity of Mind. Oxford: Oxford University Press.

Charcot, J.-M. 1886. Neue Vorlesungen über die Krankheiten des Nervensystems. Leipzig und Wien.

Comte, A. 1830. Cours de philosophie positive, vol. 1. Rouen.

Crane, T. 2000. Introspection, intentionality and the transparency of experience. Philosophical Topics 28: 49-67.

Crane, T., and C. French. 2017. The Problem of Perception. Stanford: Stanford Encyclopedia of Philosophy, ed. E. N. Zalta. https://plato.stanford.edu/archives/spr2017/entries/perception-problem/.

Dretske, F. 1995. Naturalizing the Mind. Cambridge: MIT Press.

Dretske, F. 1999. The mind's awareness of itself. Philosophical Studies 95: 103-124.

Dretske, F. 2003. How do you know you are not a zombie? Privileged Access: Philosophical Accounts of Self-Knowledge, ed. B. Gertler. Farnham: Ashgate, 1-14.

Evans, G. 1982. The Varieties of Reference. Oxford: Oxford University Press.

Firth, R. 1949. Sense-data and the percept theory. Mind 434-465.

Gertler, B. 2001. Introspecting phenomenal states. Philosophy and Phenomenological Research 63: 305328.

Goldman, A. 2004. Epistemology and the evidential status of introspective reports. Journal of Consciousness Studies 11: 1-16.

Gow, L. 2016. The limitations of perceptual transparency. Philosophical Quarterly 66: 723-744.

Harman, G. 1990. The intrinsic quality of experience. Philosophical Perspectives 4: 31-52.

Hill, C. 2009. Consciousness. Cambridge: Cambridge University Press.

James, W. 1890/1981. The Principles of Psychology. Cambridge: Harvard University Press.

Kant, I. 1786. Metaphysische Anfangsgründe der Naturwissenschaft. 
Kind, A. 2003. What's so transparent about transparency? Philosophical Studies 115: 225-244.

Kind, A. 2010. Transparency and representationalist theories of consciousness. Philosophy Compass 5: 902-913.

Kriegel, U. 2015. The Varieties of Consciousness. Oxford: Oxford University Press.

Lewis, C.I. 1929. Mind and the world order. London: Charles Scribner's Sons.

Loar, B. 1997. Phenomenal States. The Nature of Consciousness, eds. G. Guzeldere, N. Block, and O. Flanagan. Cambridge: MIT Press, 597-615.

Lycan, W.G. 1995. Layered perceptual representation. Philosophical Issues 7: 81-100.

Lycan, W.G. 2003. Dretske's ways of introspecting. Privileged Access: Philosophical Accounts of SelfKnowledge. Farnham: Ashgate.

Martin, M.G.F. 1997. The reality of appearances. Thought and Ontology, ed. M. Sainsbury. Franco: Angeli, 81-104.

Martin, M.G.F. 2000. Beyond dispute: Sense-data, intentionality and the mind-body problem. The History of the Mind-Body Problem, eds. T. Crane, S. Patterson, and M.G.F. Martin. Milton Park: Routledge, 195-231.

Mill, J.S. 1907/1865. Auguste Comte and Positivism. London: Kegan.

Moore, G.E. 1903. The refutation of idealism. Mind: 433-453.

Morales, J. Forthcoming. Introspection is signal detection. British Journal for the Philosophy of Science.

Moran, R. 2001. Authority and Estrangement. Princeton: Princeton University Press.

Müller, G.E. 1911. Zur Analyse der Gedächtnistätigkeit und des Vorstellungsverlaufes. Zeitschrift fü,r Psychologie I.

Phillips, I. 2015. No watershed for overflow: Recent work on the richness of consciousness. Philosophical Psychology: 1-14.

Price, H.H. 1932. Perception. London: Methuen.

Prinz, J. 2004. The fractionation of introspection. Journal of Consciousness Studies 11: 40-57.

Schwitzgebel, E. 2008. The Unreliability of Naive Introspection. Philosophical Review.

Schwitzgebel, E. 2019. Introspection. The Stanford Encyclopedia of Philosophy. ed. E. N. Zalta, W. https:// plato.stanford.edu/archives/win2019/entries/introspection/.

Shoemaker, S. 1994. Self-knowledge and 'inner sense' lectures 1-3. Philosophy and Phenomenological Research 54: 249-314.

Shoemaker, S. 1996. Qualities and qualia: What's in the mind? The First-Person Perspective and other Essays. Cambridge: Cambridge University Press, 97-120.

Spener, M. Forthcoming. Introspection. Oxford: Oxford University Press.

Timmermans, B., and A Cleeremans. 2015. How can we measure awareness? An overview of current methods. Behavioral Methods on Consciousness Research, ed. M. Overgaard. Oxford: Oxford University Press, 21-46.

Tye, M. 1992. Visual qualia and visual content. The Contents of Experience, ed. T Crane. Cambridge: Cambridge University Press, 158-176.

Tye, M. 1995. Ten Problems of Consciousness. Cambridge: MIT Press.

Tye, M. 2000. Consciousness, Color, and Content. Cambridge: MIT Press.

Wundt, W. 1888. Selbstbeobachtung und innere Wahrnehmung. Philosophische Studien: 292-309.

Wundt, W. 1907. Über Ausfrageexperimente und über die Methoden zur Psychologie des Denkens. Psychologische Studien 3: 301-360.

Wundt, W. 1908. Logik: Eine Untersuchung der Prinzipien der Erkenntnis und der Methododen wissenschafticher Forschung, 3. Band: Logik der Geisteswissenschaften. Ferdinand Enke, Dritte Auflage.

Publisher's Note Springer Nature remains neutral with regard to jurisdictional claims in published maps and institutional affiliations. 